Journal of the Egyptian Society of Parasitology, Vol.43, No.3, December 2013

J. Egypt. Soc. Parasitol., 43(3), 2013: 777 - 785

\title{
THE ULTRASTRUCTURE OF SENSILLA ASSOCIATED WITH MOUTHPARTS AND ANTENNAE OF LUCILIA CUPRINA
}

\section{By}

MOSTAFA I. HASSAN, MOHAMAD A. FOUDA, KOTB M. HAMMAD, AHMED L. BASIOUNY AND MOHAMMAD R. KAMEL

Department of Zoology and Entomology, Faculty of Science, Al-Azhar University, Nasr City, Cairo, Egypt (e-mail: mostafa012@gmail.com)

\begin{abstract}
Antennal and maxillary palps of Lucilia cuprina male and female (family: Calliphoridae) were studied using scanning electron microscopy. Five types of sensilla were observed namely: trichoid, basiconic, coeloconic, styloconic and sensory pit. Trichoid sensilla (one subtype: short trichoid sensilla) was found on the scape of the antenna, while both trichoid (two subtypes: short and long trichoid sensilla) and styloconic sensilla were observed on the antennal pedicel. Basiconic sensilla (two subtypes: small and large basiconic sensilla), coeloconic sensilla and sensory pits were detected on the flagellum of antenna. Cheatica (two subtypes: small and large Cheatica) and small basicinic sensilla were located on the maxillary palps. Microtrachia were observed on all joints of antenna and maxillary palps. No marked differences were observed in the morphological structure of any of the sensilla among the two sexes studied. The suggested function of each antennal sensillum was based on comparison with results of other investigations on similar sensilla.
\end{abstract}

Keywords: Ultrastructure; Sensilla; Antennae; Mouthparts and Lucilia cuprina.

\section{Introduction}

The life cycle of fly species in families Calliphoridae (blowflies) and Muscidae (house flies and relatives) are routinely involved in forensic investigations. Eggs, larvae and pupae of fly species belonging to these families were collected from human corpses at death scenes provides entomological information that is not only useful in estimating of the postmortem interval, but may also be used for analyzing toxic substances that could have led to death (Smith, 1986; Lord, 1990; Introna et al., 1998; Goff, 2000; Byrd and Castner, 2001; Greenberg and Kunich,
2002; Sukontason et al, 2004).

Variety of chemical signals in air or in solution exerts their influence for monitoring the behavioral responses of insects and functioning of different body parts. Structural and functional diversity of sensory system of insects is related with their habit, habitat and orientation responses (Zacharuk, 1980).

Insects bear numerous sensory organs or sensilla used in the sensory perception for smell, taste, sound, touch, vision, proprioception, and geo-, thermo-, and hygroreception. Traditionally, sensillum types have been classified on the basis of the morphol- 
ogy of their cuticular parts as well as location on the insect (Zacharuk, 1985). The flies attracted to the host by the sensilla and may feed on the host tissues, organs or body fluids, also the flies may lay the eggs or larvae (maggots) while stand on the skin, wounds or natural openings of an immobile person and causes myiasis.

The present work aimed to study the different sensilla associated with antenna and maxillary parts of male and female of the blowfly, Lucilia cuprina.

\section{Materials and Methods}

The Lucilia cuprina (Family: Calliphoridae) collected from Tonamel, Village, Aga Center, Al-Dakahlia, were reared for several generation under controlled conditions of temperature $26 \pm 2^{\circ} \mathrm{C}$, relative humidity $70 \pm 10 \%$ and 12-12 light-dark regime in Research Laboratory of Medical Entomology, Faculty of Science, Al-Azhar University. The identification followed the pictorial key of Dodge (1953).

To prepare for observation with the Scanning Electron Microscope (SEM), flies were first rinsed by shaking in normal saline solution to remove surface artifacts. Then, transferred into transparent plastic bags then killed by placing the bags in a freezer set at $4{ }^{\circ} \mathrm{C}$ for $20 \mathrm{~min}$. Heads of flies were dissected under a dissecting microscope and fixed separately for $24 \mathrm{~h}$ in $2.5 \%$ glutaraldehyde solution in phosphate buffer of ph. 7.4. Following fixation the specimens were washed twice with phosphate buffer, distilled water and dehydrated with ascending grades of ethanol from $50 \%$ to $100 \%$. After that, the specimens were cleared in xylene for overnight and air-dried using $\mathrm{CO}_{2}$ critical point drier (Tousimis Audo samdri-815). The air-dried samples were mounted on scanning electron microscope stubs and then coated with thin layer of gold in an ion-sputtering unit (SPI-Module) for 30 seconds. Finally the specimens were examined by scanning electron microscope (JEOLJSM-5500LV) by using high vacuum mode at the Regional Center of Mycology and Biotechnology, Al-Azhar University. The sensilla terminology by Zacharuk (1985) was adopted

\section{Results}

Like most dipterans, the head of $L$. cuprina adult is equipped with three parts of appendages; the antennae frontally and centrally on the head and they are situated between the large compound eyes, maxillary palps and proboscis (Figs.1 \&2). The aristate antenna consisted of three parts, namely: scape, pedicel, and flagellum which bear a slender seta called the arista laterally as in male (Fig. 3).

The first segment (Scape) is the shortest one and covered with non-innervated microtrichia or spinules. One type of sensillum is found in a curved single row on the scape, known as a trichoid sensillum (one subtype: short trichoid sensillum). Trichoid sensilla are characterized as hair-like sensilla with incised longitudinal grooves and acute tips (Fig. 4). The second segment of antenna (Pedicel) also covered with non-innervated microtrichia or spinules. Two types of sensilla are observed on the pedicel, known as a trichoid 
sensillum (two subtypes: short and long trichoid sensilla) and styloconic sensillum which arranged in a frontal group on the pedicel. Each styloconic sensillum contained a seta that is bulbous at the base and then tapers distally to an acute tip. The base of each seta is received in a socket with an elevated rim (Figs. 4 \& 5).

Flagellum is the most prominent antennal segment with its length being $65-70 \%$ of the antenna's longest axis. The arista is located proximally near flagella base (Fig. 3). The flagellum is covered with microtrichia (Figs. 6, 7 \& 8 ), and included three types of sensilla (basiconic sensilla, coeloconic sensilla and sensory pits). Two subtypes of basiconic sensilla are found in flagellum (small and large basiconic sensilla). The large basiconic sensilla are characterized by setae with a smooth surface that are thickened proximally and have a slight curvature that gradually tapers to an acute tip distally; whereas, the small basiconic sensilla bear shorter, blunt-tipped setae that are interspersed amongst the other types of sensilla and microtrichia (Figs. 6, $7 \& 8$ ). The orientation of basiconic sensilla gives the velvety appearance to flagellum. Coeloconic sensilla are characterized by peg-shaped projections located in a deeply sunken depression of the integument called a sacculus (Fig. 7). Sensory pit morphology typically appeared as a relatively large pit containing several sensory pegs within the sunken (Fig. 9).

The maxillary palps are elongated and gradually enlarged to a rounded end distally, it covered with micro- trachia. Also, basiconic sensilla (subtype: small basiconic sensilla) and chaetica sensilla (subtypes: small and large chaetica sensilla) (Figs. 10 \& 11). The chaetica sensilla characterized by setae with deep longitudinal grooves along their external surfaces.

The sponging mouthparts can be extended from the ventral region of the head and exhibited an everted labellum at the end of the labium (Figs. 1, $2 \&$ 12).

\section{Discussion}

Antennal sensilla in many insects, including flies, have been extensively recorded as bearing several olfactory receptors (DeVaney et al, 1970; Greenberg, 1970; Shanbhag et al, 1999; Gullan and Cranston, 2000; Ochieng et al, 2000; Merivee et al, 2002), and the present data went with these records.

Mechano-receptive function for trichoid sensilla was suggested in numerous insects that were studied including the human bot fly, Dermatobia hominis (Fernandes et al, 2002), the ground beetle, Bembidion properans (Merivee et al, 2002), the red imported fire ant, Solenopsis invicta (Renthal et al, 2003), and the parasitoid wasp Microplitis croceipes (Ochieng et al, 2000). This agreed with many authors who found that trichoid sensilla in the scape and pedicel such as Dermatobia hominis (Fernandes et al, 2002), Hydrotaea chalcogaster (Sukontason et al, 2007) and Chrysomya pinguis (Sukontason et al, 2008).

The styloconic sensilla are found in the male of Dermatobia hominis (Fernandes et al, 2002), C. megacephala, 
C. rufifacies, C. nigripes, L. cuprina, P. dux and M. domestica (Sukontason et al, 2004) and H. chalcogaster (Sukontason et al, 2007). The Mechanoand/or chemoreception function of styloconic sensilla were suggested (Zacharuk, 1985; Mitchell et al, 1999).

In the present study, the most prevalent type of antennal sensilla in both sexes of all fly species examined is basiconc sensilla which play an olfactory role. This agreed with the findings of Zacharuk (1985), Hunter and Adserballe (1996), Rahal et al. (1996), Shields and Hildebrand (1999), Lopes et al. (2002), and Broeckling and Salom (2003).

In the present study, the large and small basiconic sensilla are similar to those of the fruit fly, Drosophila melanogaster (Shanbhag et al, 1999), human bot fly, Dermatobia hominis (Fernandes et al, 2002), Pseudoperichaeta nigrolineata (Rahal et al, 1996), C. megacephala, C. rufifacies, C. nigripes, L. cuprina, P. dux and M. domestica (Sukontason et al, 2004), H. chalcogaster (Sukontason et al, 2007), and type $1 \& 2$ of the female warble fly, $H$. bovis (Hunter and Adserballe, 1996).

In the present study, the fine structure of the coeloconic sensilla is similar to those reported in antennae of the human botfly, D. hominis (Fernandes et al, 2002), C. megacephala, C. rufifacies, C. nigripes, L. cuprina, P. dux and $M$. domestica (Sukontason et al, 2004), H. chalcogaster (Sukontason et $a l$, 2007) and the biting midge, Culicoides impunctatus (Diptera: Ceratopogonidae) (Blackwell and Mordue,
1992). The function of coeloconic sensilla are thermo- or hygroreception (McIver, 1969; Altner et al, 1983; Zacharuk, 1985; Ochieng et al, 2000).

Many authors for example (ChuWang et al, 1975; Chapman, 1982; Wasserman and Itagaki, 2003) stated that the most likely function of the sensory pits is olfactory function. Ultrastructure of the sensory pits of the fly species examined in this study appeared to be similar to those found on the third maxillary palp of biting midges, Culicoides spp. (McKeever et al, 1994), and those on the funiculus of female warble fly Hypoderma bovis (Hunter and Adserballe, 1996), C. megacephala, C. rufifacies, C. nigripes, L. cuprina, $P$. dux and M. domestica (Sukontason et al, 2004) and $H$. chalcogaster (Sukontason et al, 2007).

In the present study, the maxillary palps of all examined species are carried microtrachia, small basiconic sensilla, small and large chaetica, and were similar to those found on palps of Chrysomya nigripes (Ngern-klun et al, 2007) and palps of the House flies, Musca domestica (Smallegange et al, 2008)

The present data detected the presence of microtrachia, large chaetica and small basiconic sensilla on all maxillary palps examined, these findings are in agreed with similar works of Sukontason et al. $(2007 ; 2008)$ worked on Hydrotaea chalcogaster and Chrysomya pinguis, but the present work disagreed with them in the absence of small chaetica. 

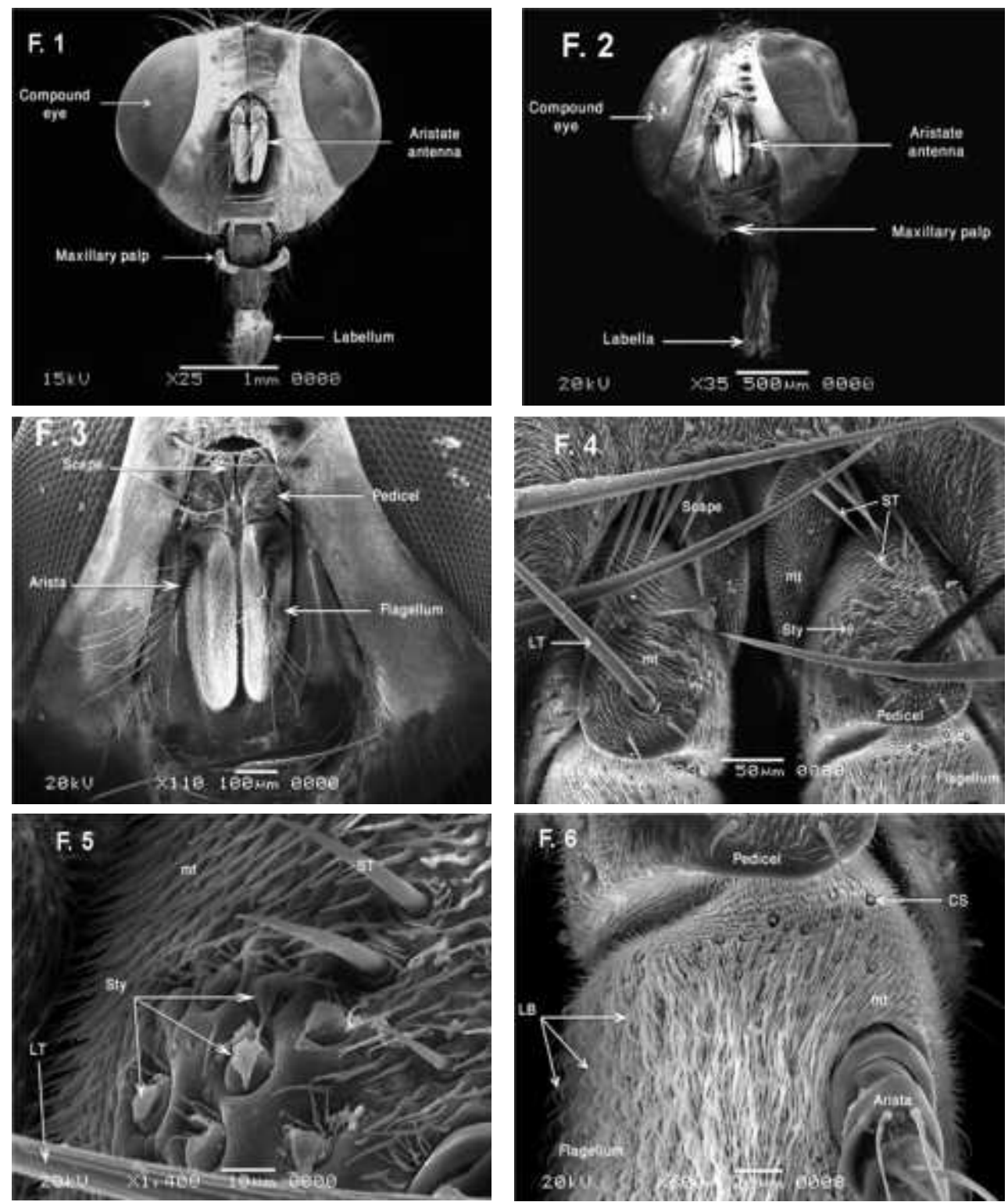

Fig. 1: SEM of Lucilia cuprina female head (dorsal view) showing eyes, antennae, maxillary palps, and labella.. Fig. 2: SEM of dorsal view of $L$. cuprina male head showing eyes, antennae, maxillary palps, and labella Fig. 3: SEM of male aristate antennae. Each antenna consists of scape, pedicel and flagellum.

Fig. 4: SEM showing antennal scape, pedicel and flagellum of female. $\mathrm{mt}=$ microtrachia sensillum and $\mathrm{ST}=\mathrm{short}$ trichoid sensillum on scape and pedicel; LT= long trichoid sensillum and Sty= styloconic sensillum on pedicel. Fig. 5: SEM showing various sensilla types on pedical of female: $\mathrm{mt}=$ microtrachia sensillum, $\mathrm{ST}=$ short trichoid sensillum, LT= long trichoid sensillum, Sty= styloconic sensilla.

Fig. 6: SEM showing flagellum of female with various types of sensilla. $\mathrm{mt}=$ microtrachia sensillum, $\mathrm{LB}=$ large basiconic sensilla and $\mathrm{CS}=$ coeloconic sensillum. 

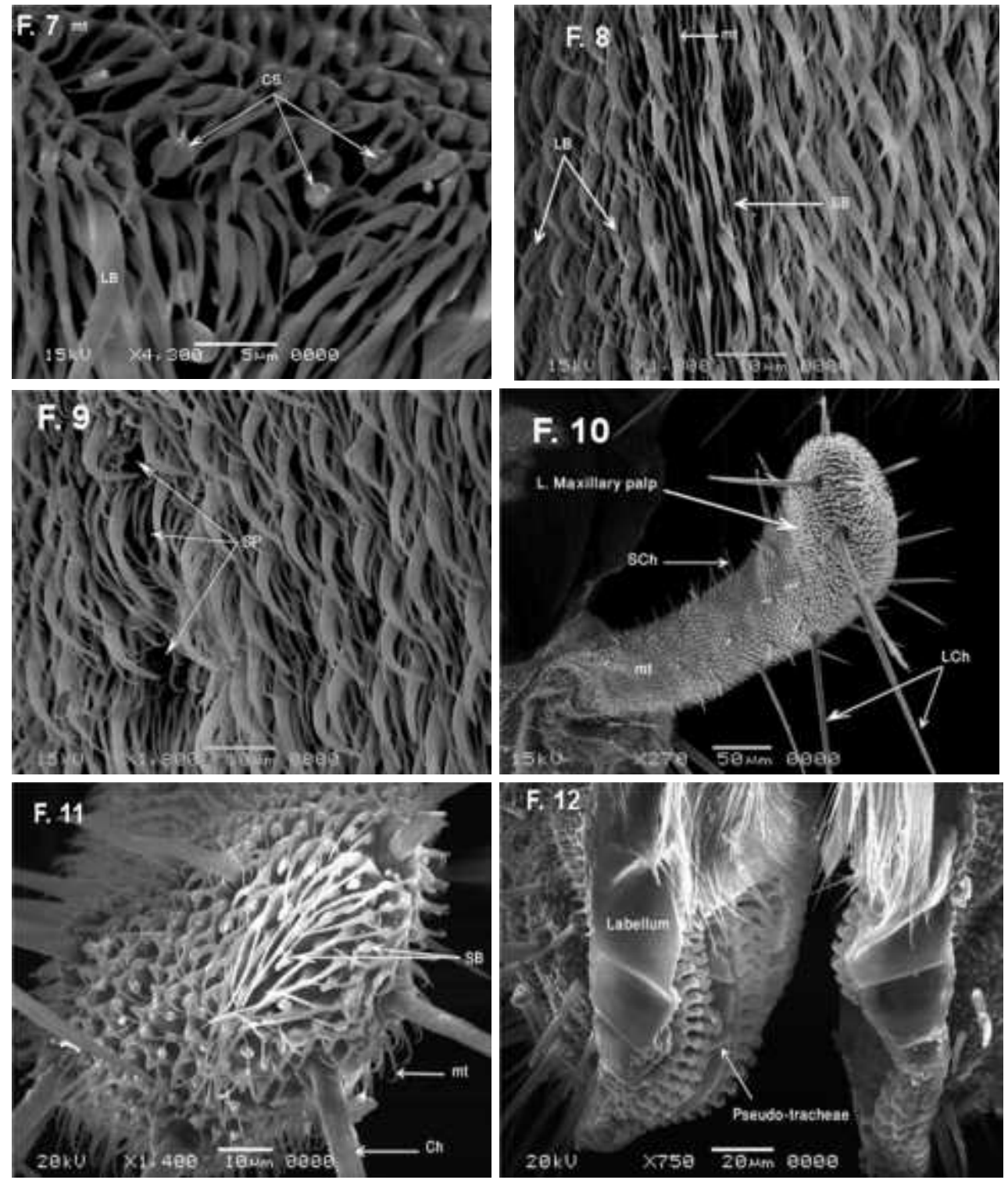

Fig. 7: SEM showing $\mathrm{CS}=$ coeloconic sensillum, $\mathrm{mt}=$ microtrachia, $\mathrm{LB}=$ large basiconic sensillum in flagellum of female.

Fig. 8: $\mathrm{SEM}$ showing $\mathrm{CS}=$ coeloconic sensillum, $\mathrm{mt}=$ microtrachia, $\mathrm{SB}=$ small basiconic sensillum, $\mathrm{LB}=$ large basiconic sensilla in flagellum of male.

Fig. 9: SEM showing flagellum of female with $\mathrm{SP}=$ sensory pit sensillum.

Fig. 10: SEM showing left maxillary palp of $L$. cuprina with various sensilla types: $\mathrm{mt}=$ microtracia sensillum, $\mathrm{LCh}=$ large chaetica sensilla, $\mathrm{SCh}=$ small chaetica sensillum.

Fig.11: SEM showing various types of sensilla on male maxillary palp. $\mathrm{mt}=$ microtrachia sensillum, $\mathrm{Ch}=\mathrm{chaetica}$ sensillum, $\mathrm{SB}=$ small basiconic sensillum.

Fig. 12: SEM showing pseudo-trachea in labella of male. 


\section{References}

Altner, H, Schaller-Selzer, L, Stetter, H, Wohlrab, I, 1983: Poreless sensilla with inflexible sockets; a comparative study of a fundamental type of insect sensilla probably comprising thermoand hygroreceptors. Cell Tissue Res. 234:279-307.

Blackwell, A, Mordue, W, 1992: Morphology of the antennae of two species of biting midge: Culicoides impunctatus (goetghebuer) and Culicoides nubeculosus (Meigen) (Diptera, Ceratopogonidae). J. Morphol. 213, 1: 85-103.

Broeckling, CD, Salom, SM, 2003: Antennal morphology of two specialist predators of hemlock woolly adelgid, Adelges tsugae (Homoptera: Adelgidae). Ann. Entomol. Soc. Amer. 96, 2: 153-60.

Byrd, JH, Castner, JL, 2001: Insects of forensic importance. In: Byrd, JH, Castner, JL (Eds.), Forensic Entomology: The Utility of Arthropods in Legal Investigations. CRC Press, Florida.

Chapman, RF, 1982: The Insects Structure and Function. $3^{\text {rd }}$ ed., Harvard University Press, Cambridge, MA.

Chu-Wang, IW, Axtell, RC, Kline, D L, 1975: Antennal and palpal sensilla of the sand fly, Culicoides furens (Poey) (Diptera: Ceratopogonidae). Int. J. Insect Morphol. Embryol. 4, 2:131-49.

Devaney, JA, Eddy, GW, Handke, B D, Lopez, E, 1970): Olfactory responses of the adult screw-worm after removal of the antennae, mouthparts, tarsi, and legs. J. Economic Entomol. 63, 6:1816-9.
Dodge, HR, 1953: Domestic flies: pictorial key to common species in southern US In. CDC Pictorial Keys: Arthropods, Reptiles, Birds and Mammals of Public Health Significance.

Fernandes, FDF, Linardi, PM, Chiarini-Garcia, H, 2002: Morphology of the antenna of Dermatobia hominis (Diptera: Cuterebridae) based on scanning electron microscopy. J. Med. Entomol. 39, 1:36-43.

Goff, ML, 2000: A fly for the prosecution: How Insect Evidence Helps Solve Crimes. Harvard University Press.

Greenberg, B, 1970: Species distribution of new structures on fly antennae. Nature 228:1338-9.

Greenberg, B, Kunich, JC, 2002: Entomology and the Law: flies as forensic indicators. Cambridge University Press.

Gullan, PJ, Cranston, PS, 2000: The insects: an Outline of Entomology. $2^{\text {nd }}$ edition Blackwell, Oxford.

Hunter, FF, Adserballe, CF, 1996: Cuticular structures on the antennae of Hypoderma bovis De Geer (Diptera: Oestridae) females. Int. J. Insect Morphol. Embryol. 25, 1:173-81.

Introna, F, Campobasso, CP, Di-Fazio, A, 1998: Three case studies in forensic entomology from southern Italy. J. Foren. Sci. 43:210-4.

Lopes, O, Barata, EN, Mustaparta, H, Araujo, J, 2002: Fine structure of antennal sensilla basicona and their detection of plant volatiles in the eucalyptus woodborer, Phoracantha semipunctata Fabricius (Coleoptera: Cerambycidae). Arthro. Struct. develop. 31: $1-13$. 
Lord, WD, 1990: Case histories of the use of insects in investigations. Entomology and death: a procedural guide. Joyce's Print Shop, Clemson, SC, 9-37. Mciver, SB, 1969: Antennal sense organs of female Culex tarsalis (Diptera: Culicidae). Ann. Entomol. Soc. Amer. 62, 6:1455-161.

Mckeever, SIS, Hagan, DV, Wang, $X, 1994$ : Comparative study of mouthparts of four species of Culicoides from Tibet. Med. Vet. Entomol. 8, 3: 25564.

Merivee, E, Ploomi, A, Rahi, M, Bresciani, J, Ravn, HP, et al, 2002: Antennal sensilla of the ground beetle, Bembidion properans Steph. (Coleoptera, Carabidae). Micron 33, 5:429-40.

Mitchell, BK, Itagaki, H, Rivet, MP, 1999: Peripheral and central structures involved in insect gustation. Microsc. Res. Tech. 47, 6:401-15.

Ngernklun, R, Sukontason, K, Methanitikorn, R, Vogtsberger, RC, Sukontason, KL, 2007: Fine structure of Chrysomya nigripes (Diptera: Calliphoridae), a fly species of medical importance. Parasitol. Res.100, 5:993-1002.

Ochieng, SA, Park, KC, Zhu, JW, Baker, TC, 2000: Functional morphology of antennal chemoreceptors of the parasitoid Microplitis croceipes (Hymenoptera: Braconidae). Arthro. Struct. Develop. 29, 3:231-40.

Ochieng, SA, Park, KC, Zhu, JW, Baker, TC, 2000: Functional morphology of antennal chemoreceptors of the parasitoid Microplitis croceipes (Hymenoptera: Braconidae). Arthro. Struct. Develop. 29, 3:231-40.
Rahal, Y, Barry, P, Hawlitzky, N, Renou, M, 1996: Antennal olfactory sensilla of the parasitoid fly, Pseudoperichaeta nigrolineata Walker (Diptera: Tachinidae). Int. J. Insect Morphol. Embryol. 25, 1:145-52.

Renthal, R, Velasquez, D, Olmos, D, Hampton, J, Wergin, WP, 2003: Structure and distribution of antennal sensilla of the red imported fire ant. Micron 34, 8:405-13.

Shanbhag, SR, Müller, B, Steinbrecht, RA, 1999: Atlas of Olfactory Organs of Drosophila melanogaster: 1Types, external organization, innervation and distribution of olfactory sensilla. Int. J. Insect Morphol. Embryol. 28, 4:377-97.

Shields, VDC, Hildebrand, JG, 1999: Fine structure of antennal sensilla of the female sphinx moth, Manduca sexta (Lepidoptera: Sphingidae). I. Trichoid and basiconic sensilla. Canad. J. Zool.77, 2:290-301.

Smallegange, RC, Kelling, FJ, Otter, CJD, 2008: Types and numbers of sensilla on antennae and maxillary palps of small and large houseflies, Musca domestica (Diptera, Muscidae). Microsc. Res. Tech. 71, 12:880-6.

Smith, KG, 1986: A manual of forensic entomology, British Museum (Natural History) Cornell University Press, London; Ithaca, New york.

Sukontason, K, Methanitikorn, R, Chaiwong, T, Kurahashi, H, Vogtsberger, RC, et al, 2007: Sensilla of the antenna and palp of Hydrotaea chalcogaster (Diptera: Muscidae). Micron 38, 3:218-23. 
Sukontason, K, Methanitikorn, R, Kurahashi, H, Vogtsberger, RC, Sukontason, KL, 2008: External morphology of Chrysomya pinguis (Walker) (Diptera: Calliphoridae) revealed by scanning electron microscopy. Micron 39, 2:190-7.

Sukontason, K, Sukontason, KL, Piangjai, S, Boonchu, N, Chaiwong, T, et al, 2004: Antennal sensilla of some forensically important flies in families Calliphoridae, Sarcophagidae and Muscidae. Micron 35, 8:671-9.

Wasserman, SL, Itagaki, HL, 2003:
The olfactory responses of the antenna and maxillary palp of the fleshfly, $\mathrm{Ne}$ obellieria bullata (Diptera: Sarcophagidae), and their sensitivity to blockage of nitric oxide synthase. J. Insect Physiol. 49, 3:271-80.

Zacharuk, RY, 1980: Ultrastructure and function of insect chemosensilla. Ann. Rev. Entomol. 25, 1:27-47.

Zacharuk, RY, 1985: Antennal sensilla. In: Kerkut, GA, Gilbert, LI (eds.), Comparative Insect Physiology, Biochemistry and Pharmacology, vol. 6. Pergamon Press, Oxford. 